\title{
ON THE PARATYPHOID GROUP OF BACILLI.
}

By F. A. BAINBRIDGE, M.D., F.R.C.P., D.P.H. AND R. A. O'BRIEN, M.D., B.S., D.P.H.

\section{(From The Lister Institute of Preventive Medicine.)}

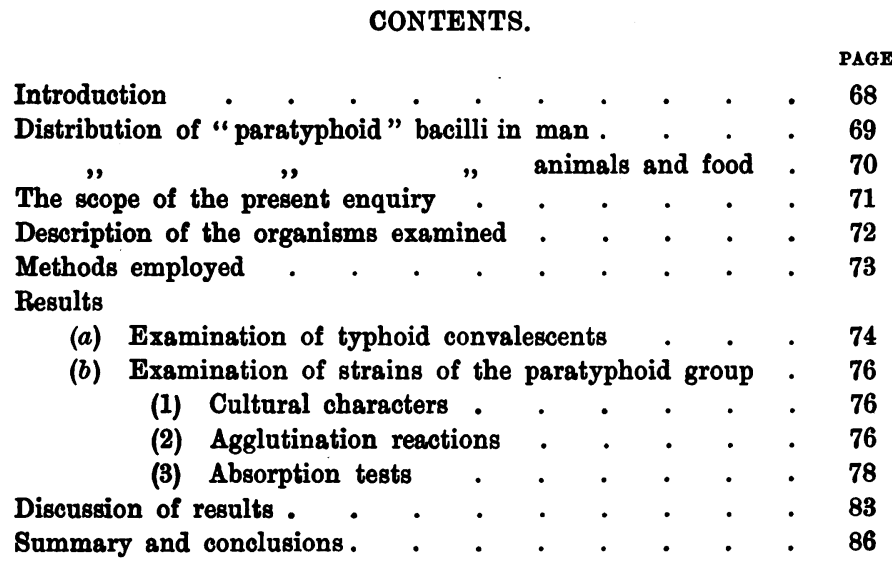

\section{Introduction.}

THERE exists at the present time considerable difference of opinion both as to the distribution in nature of $B$. paratyphosus (B) and as to its relation to disease in man. The name was given by Schottmuiller (1900 and 1901) to a bacillus, which he isolated from patients whose clinical symptoms were those of enteric fever, and which he regarded as the causal organism of their illness. Further enquiry soon showed that this bacillus was closely related to B. suipestifer (or aertryck) which occurs in the intestine of healthy pigs and has been found on several 
occasions in association with outbreaks of food-poisoning in man. Almost all writers in this country, however, regard them as distinct organisms which can be differentiated from one another sometimes by their agglutination reactions and always, as both Boycott (1906) and Bainbridge (1909) have shown, by the absorption method; and most workers appear to have experienced no difficulty in identifying the strains which they isolated as B. suipestifer or B. paratyphosus (B) respectively. The majority of English writers therefore limit the term $B$. paratyphosus (B) to those bacilli which correspond in all respects, including their reaction to absorption tests, to original strains of the bacillus isolated by Schottmüller.

On the contrary Kutscher and Meinecke (1906), Bock (1906) and others regard B. suipestifer and B. paratyphosus (B) as indistinguishable from one another, and as being in all probability identical organisms; with the exception of a few observations by Bock, who was able to differentiate B. paratyphosus (B) from B. suipestifer, the absorption method was apparently not employed by these observers. This conclusion has been generally accepted by German writers, who almost without exception describe as $B$. paratyphosus (B) all bacilli whatever their source may be, which correspond in their cultural and agglutination reactions to the "paratyphoid" group; and they draw no distinction between $B$. suipestifer and $B$. paratyphosus (B), although they retain the term $B$. suipestifer for the organisms of this group which are derived from pigs.

\section{Distribution in man.}

Since some writers draw a distinction between $B$. suipestifer and $B$. paratyphosus (B), whereas others do not, and since the term $B$. paratyphosus (B) is not used in the same sense by different writers, it is hardly to be expected that they should agree as to the distribution and pathogenic significance of "paratyphoid" bacilli. "The evidence regarding the distribution of these bacilli in man is, indeed, remarkably conflicting. On the one hand a very complete investigation of the faeces of 303 cases of summer diarrhoea by Morgan (1905-1907) yielded only two strains which gave the cultural and agglutination reactions characteristic of $B$. suipestifer. Savage (1909) examined sixty samples of faeces and urine from typhoid patients and from healthy individuals, but failed to find paratyphoid (B) bacilli in man except in cases of paratyphoid fever; Williams, Rundle and Murray (1910) examined 
the stools of 100 healthy children with completely negative results. Nor was B. paratyphosus (B) found either by Seiffert (1909) who examined, the faeces of 600 healthy men, or by Sobernheim (1910) who investigated 1,000 samples of urine and faeces from healthy men. The conclusion, to which these observations point, is that the paratyphoid (B) bacillus is very rarely found in the human intestine or in urine apart from cases of paratyphoid fever.

On the other hand, many German workers have brought forward evidence that "paratyphoid" bacilli (in the wider sense of the term) can be obtained from the faeces, the urine and even the blood of healthy individuals. Thus, Conradi (1909) isolated "paratyphoid" bacilli from the faeces of twenty-nine out of 250 typhoid convalescents, from several typhoid patients and "contact" cases, from patients suffering from other diseases, and from healthy individuals. In the course of some years, Prigge and Sachs-Müke (1909) examined the faeces or urine (or both) of 5,252 people, and found "paratyphoid " bacilli in seventy cases, apart from cases of paratyphoid fever. Similar observations, though of a less striking character, have been published by Gaethgens (1907) and others.

\section{Distribution in animals and food.}

The distribution of the "paratyphoid" group of bacilli in food and in the lower animals has received hardly any attention in this country, and no systematic search for these organisms appears to have been carried out ${ }^{1}$.

Recent observations by Petrie and O'Brien (1910), however, point to the frequent occurrence of $B$. suipestifer in healthy guinea-pigs, and O'Brien (1910) has met with several guinea-pigs which were persistent carriers of this bacillus. In the course of the bacteriological examination of 850 glucose-fermenting bacilli obtained from many samples of milk (number not stated), Orr (1908) found eight strains which gave the cultural reactions characteristic of the "paratyphoid" group, but were not subjected to agglutination tests. Observations on the presence of these organisms in meat seem to be entirely lacking.

In Germany, bacilli of the "paratyphoid" group have been found in milk by Fischer (1903), in water by Conradi (1904), Priefer and

1 One of us (F. A. B.) has recently examined the intestinal contents of 50 healthy pigs; no bacilli of this group were found. 
Keyser (1902), in sausages by Hübener (1908) and by Rommeler (1909), and in goose (Spickgänse) by Sobernheim (1910). They have also been obtained from the intestinal contents of healthy pigs by Uhlenhuth (1908) (8\%) and by Seiffert (1909) $(3.5 \%)$.

On the ground of this evidence and of their observation that the consumption by man of food containing these bacilli led to no ill effects, Hübener and Conradi consider not only that "paratyphoid" bacilli have a wide distribution in nature, but also that they are usually harmless for man, and that the isolation of these bacilli from the excreta of a human being is no indication that he has or has had a paratyphoid infection, and is in fact of no special significance.

It seemed to us possible that an enquiry into the distribution of $B$. suipestifer on the one hand and of B. paratyphosus (B) on the other hand might furnish some evidence as to their pathogenic significance, and might also assist in explaining the opposing views now held by various workers. The present investigation was carried out from this point of view.

\section{The scope of the present enquiry.}

Although the cultural characters of $B$. enteritidis (Gaertner) are identical with those of $B$. suipestifer, both B. Gaertner and B. paratyphosus (A) are clearly marked off from B. suipestifer and B. paratyphosus (B) by their agglutination reactions. They have, therefore, been left out of consideration in this paper, and the term "paratyphoid group of bacilli," as here used, includes only $B$. suipestifer and B. paratyphosus (B).

The investigation of the "paratyphoid" group has been carried out along two lines. In the first place, the faeces and urine of a large number of typhoid convalescents were examined in order to obtain some evidence as to the prevalence of bacilli of the "paratyphoid" group in the human alimentary canal, apart from cases of paratyphoid fever.

Secondly, a considerable number of strains of the "paratyphoid" group of bacilli was obtained from various sources. They were compared with standard, recognised strains of $B$. suipestifer and $B$. paratyphosus (B) as regards their caltural characters and their agglutination and absorption reactions. Attention was particularly directed to their absorption reactions, since as previously mentioned it has been shown by Boycott (1906) and also by Bainbridge (1909) that $B$. suipestifer and $B$. paratyphosus (B) can be readily differentiated from one another by 
means of the absorption method of Castellani (1902), and that the use of this method is essential for the complete identification of any given strain belonging to the "paratyphoid" group.

\section{Description of the organisms examined.}

The following strains have been examined :-

A. Standard strains.

Description

(a) B. paratyphosus (B)

(b)

(c) B. suipestifer

(d) ,

(e) , ,
Source

Schottmüller; original strain 1901.

Professor McWeeney: isolated from a fatal case of paratyphoid fever.

Laboratory strain (Kral).

Isolated from a healthy pig: sent by Professor Uhlenhuth.

Sent by Professor Wassermann.

These strains had been repeatedly tested by the absorption method and always yielded constant results.

B. Fresh strains.

Description

(1) Eisenmeyer

(2) Bieber

(3) Kunz

(4) Vogt

(5) Schnorr

(6) Kant

(7) $\mathrm{Ma}$

(8) Düsseldorf

(9) Heydr. Ali

(10) $\mathrm{Ba}$

(11) Liver

(12) Sausage

(13) Murrow

(14) Savage, c

(15) ,

(16) Lyons

(17) Winfield

(18) Gill

(19) Zender

(20) Lieblang

(21) Lister

(22) Bacillus F

(23) Victoria

(24) Garton

\section{Source}

Paratyphoid fever case.

Paratyphoid carrier (Dauerträger).

",

,

,

Healthy man.

$\begin{array}{ll}\text { ", } & \text {," } \\ \text {," } & \text {," }\end{array}$

"Sick" " man

Food.

Liver cheese (Leberkäse).

Blood sausage (Blutwurst).

Food-poisoning (patient).

Paratyphoid fever case.

Food-poisoning (patient).

Paratyphoid fever case.

Gastro-enteritis (patient).

Healthy man.

Paratyphoid fever case.

Water.

Summer diarrhoea.

Fatal Ac. gastro-enteritis (? food). 


\section{Methods employed.}

The mode of carrying out the cultural, agglutination and absorption tests has been described in detail in a former paper (Bainbridge, 1909) and reference need be made only to two points. In the first place, some difficulty was experienced in obtaining highly agglutinating sera by the injection of killed cultures into rabbits, and the sera agglutinated equally both $B$. suipestifer and $B$. paratyphosus (B). Sera, obtained from rabbits injected with living cultures, had a very high agglutination titre for the homologous organism, and a distinctly lower titre for heterologous strains.

Secondly, attention may be called to Dreyer's observation that the absorption of agglutinins consists partly in a specific combination of agglutinin and bacteria, and partly in a non-specific or less specific physical absorption of agglutinin. It is possible by the addition of very large amounts of a heterologous bacillus to remove some of the homologous agglutinin from a serum, but we have not succeeded in removing all the homologous agglutinin in this way. The difference between the amount of heterologous bacilli which must be added to a serum to absorb only the heterologous agglutinin, leaving the homologous agglutinin intact, and that necessary to absorb much of the homologous agglutinin, is so large that errors cannot occur if reasonable care is taken (as may be seen in Tables I and II). As a rule, one or two trials suffice to determine the amount of heterologous bacilli, which must be added to a serum in order to remove the heterologous agglutinins -and so get the specific effect-without appreciably affecting the homologous agglutinin; when this amount has been once ascertained, the result can be reproduced without difficulty on subsequent occasions. It is also safer and preferable to measure the agglutination limit of the serum after absorption rather than merely to observe the agglutination at one or two dilutions, and it is important in every experiment to test the absorbed serum against standard strains as well as against the organism under investigation. The absorption method is also much more easily carried out, and the results obtained are much sharper, when sera are used which have a high agglutination titre $(10,000$ or more).

The examination of the faeces and urine of the typhoid convalescents was carried out in the following manner: the material was plated out on lactose-neutral-red-bile-salt agar and a number of white colonies 
were picked off into mannite broth by Dr Ledingham, who kindly handed on to us all cultures which formed acid and gas in this medium. The cultures were replated on lactose-saccharose-bile-salt-neutral-red agar, and the colourless colonies were picked off into dulcite broth. The cultures, which fermented dulcite, were then tested by all the ordinary cultural tests used for identification of bacilli of the "paratyphoid" group.

TABLE I. The effect of progressive absorption of a serum with heterologous bacilli.

A Paratyphoid (B) serum was absorbed with B. suipestifer, the bacilli being added from the agar slopes.

Paratyphoid (B) serum

Original titre

1st absorption with 3 slopes

2nd ", 3 further slopes

3rd ", 3 ,, ,

\begin{tabular}{ccc}
\multicolumn{3}{c}{ Agglutination limits after absorption } \\
B. paratyphosus (B) & B. suipestifer & B. aertryck \\
4,000 & 1,000 & 1,000 \\
4,000 & $<200$ & $<200$ \\
2,000 & $<100$ & $<100$ \\
1,000 & - & -
\end{tabular}

TABLE II. The effect of absorbing a serum with varying amounts of heterologous bacilli.

The volume of serum used was constant, namely 2 c.c. of $1-10$ dilution; the amount of bacilli added varied from 2-8 agar slopes of approximately uniform size and density of growth.

A B. suipestifer serum was absorbed with B. paratyphosus (B).

Serum

B. suipestifer serum. Original titre

,, absorbed with 2 slopes

", 4 ,

Results.

(a) Examination of typhoid convalescents.

It is now generally admitted that $B$. suipestifer and B. paratyphosus (B) are indistinguishable by their cultural reactions. Briefly these reactions are as follows :

(1) The production of acid and gas in broth containing glucose, mannite, dulcite, laevulose, galactose, arabinose, maltose and sorbite. 
(2) No apparent change in broth containing lactose, saccharose, salicin, raffinose and inulin.

(3) Litmus milk shows an initial transient acidity not often lasting more than 24 hours; in $3-5$ days the milk is definitely alkaline and at the end of a week intensely alkaline; no clot is formed, and there is no obvious sign of digestion.

(4) No indol is formed.

(5) Neutral red broth is usually reduced in $\mathbf{4 8}$ hours, but this test is less reliable than the others.

When subjected to these tests, not one of the 341 colonies which we obtained from the faeces or urine of approximately 300 typhoid convalescents, corresponded in its cultural characters to B. paratyphosus (B). A large proportion of them fermented saccharose, and the remainder produced indol and fermented salicin. Several of the strains, which most nearly resembled $B$. paratyphosus (B) in their cultural characters, were tested with Gaertner and paratyphoid (B) sera, but none of them was agglutinated in dilutions higher than 1-100 (Table III). Similar results were obtained by Savage (1909). We have in fact never met with any organism which was agglutinated beyond the above limit by a paratyphoid (B) (or Gaertner) serum, unless its cultural and fermentation characters corresponded in all respects with those bacilli.

TABLE III. Agglutination reactions of strains isolated from typhoid convalescents. These strains resembled but were not completely identical with $B$. paratyphosus $(B)$ in their cultural reactions.

$\begin{array}{llc}\text { Strain } & \begin{array}{c}\text { Paratyphoid serum } \\ \text { (titre 20,000) }\end{array} & \begin{array}{c}\text { Gaertner serum } \\ \text { (titite 5,000) }\end{array} \\ \text { 1. Lythe } & <100 & <100 \\ \text { 2. Crowdy } & <100 & <100 \\ \text { 3. Newman } & <100 & <100 \\ \text { 4. B. B. 3 } & <100 & - \\ \text { 5. K. 4 } & <100 & - \\ \text { 6. Roberts, 2 } & <100 & - \\ \text { 7. Robinson } & <100 & - \\ \text { 8. } \text { B. } 270 & <100 & <100\end{array}$

These results entirely confirm those of Morgan (1907), Seiffert (1909), Savage (1909), Williams, Rundle and Murray (1910), as opposed to those of Conradi (1909), Grethgens (1907) and Prigge and Sachs-Müke (1909). There is no reason to suppose that the differences in the technique adopted by different writers for the isolation of this group of bacilli account for these conflicting results. The differences consist 
almost entirely in the medium used for plating out the material under investigation; some workers used lactose-bile-salt-neutral-red agar, others use malachite green and Conradi-Drigalski agar.

A partial explanation may perhaps be found in the fact that some workers appear not to make use of dulcite, saccharose or salicin for the identification of "paratyphoid" bacilli, and may in some cases describe as $B$. paratyphosus (B) strains which would be excluded by others, who apply more extensive cultural tests. One strain sent to us as $B$. paratyphosus (B) differed widely in its cultural characters from standard strains of $B$. paratyphosus (B), and did not agglutinate (beyond a dilution of 1 in 40) with paratyphoid and suipestifer sera. Morgan (1907) has shown clearly that organisms occur with considerable frequency in the human intestine, which in some respects resemble "paratyphoid" bacilli, but which can be distinguished from them by adequate cultural and fermentation tests.

It is not improbable, however, that actual differences in the regional distribution of these organisms largely account for the apparently discordant observations of various writers. Although bacilli of the "paratyphoid" group have very rarely been isolated (apart from cases of paratyphoid fever) in London, Williams, Rundle and Murray (1910), working in Liverpool, obtained B. suipestifer from seven (probably seventeen) cases of summer diarrhoea. Again Sobernheim (1910) only occasionally found paratyphoid bacilli in Berlin, either in food or in healthy men, whereas Conradi (1909) frequently isolated these organisms from typhoid convalescents and healthy men in Western Germany.

Whether the distribution of these bacilli is such that in some districts they are frequently obtained both from food and from man, and in other districts they are rarely met with in food or in man, has yet to be proved. But the available evidence certainly suggests that such may be the case.

(b) Examination of strains of the paratyphoid group.

(1) Cultural characters.

All the strains gave the cultural reactions characteristic of the "paratyphoid" group of bacilli, except No. 20 (Lieblang), which fermented no sugars and was probably $B$. faecalis alkaligenes.

(2) Agglutination reactions.

Four sera were systematically employed for the carrying out of the agglutination tests, and in addition other sera were occasionally used. 
The results, which are given in Table IV, show that with one or two exceptions all the strains were agglutinated equally well by the sera ( $A$ and $B$ ) obtained from rabbits, which had been injected with killed cultures of $B$. suipestifer and B. paratyphosus (B). In the case of the sera $(C$ and $D)$ obtained by the injection of living cultures into rabbits the agglutination limits were not the same for all strains and some indication was revealed of the existence of two types of bacilli. Some strains behaved like the standard strains of $B$. suipestifer, others like

TABLE IV. Agglutination reactions of the strains.

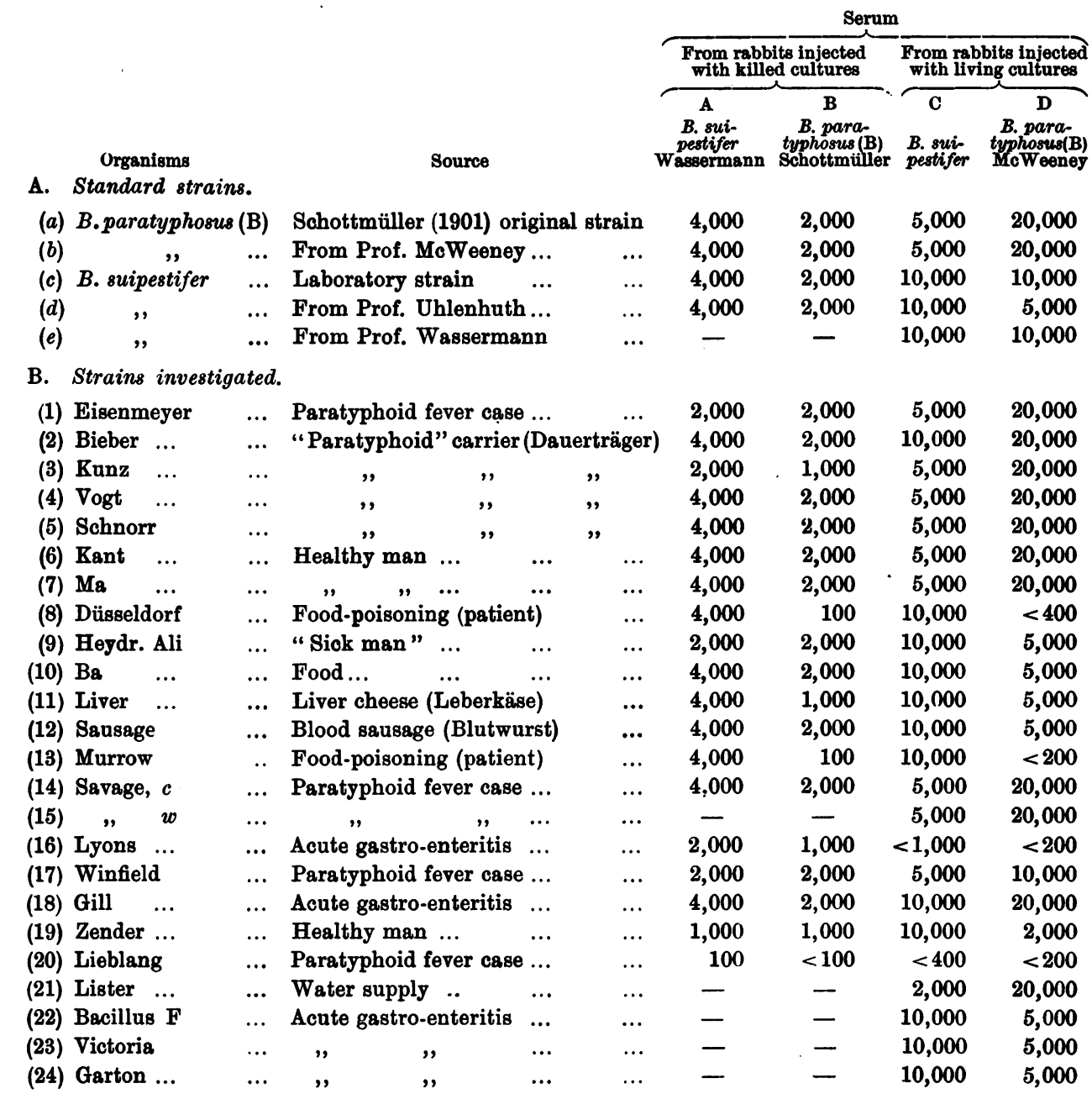


standard strains of B. paratyphosus (B). It was also noticed in the case of serum $D$, that some strains were agglutinated into large clumps leaving a clear surrounding fluid, whereas other strains, even in such low dilution of the serum as 1 in 100 , formed minute clumps, which had little or no tendency to settle and leave a clear fluid. The absorption method made it clear that with serum $\mathbf{D}$ and to a less degree with other sera, homologous bacilli tended to form large clumps, while heterologous bacilli formed small clumps. This difference has also been observed by Seligmann and Sobernheim (1910), although they did not attribute any significance to the observation.

As might be expected from its cultural characters, strain 20 (Lieblang) was not agglutinated by any of the sera in dilutions higher than 1 in 100. It has in fact been our experience that no bacillus which is not in all respects identical in cultural characters with $B$. suipestifer (or B. paratyphosus (B)) is ever agglutinated beyond dilutions of 1 in 100 by a suipestifer or paratyphosus (B) serum. We have however met with two organisms, i.e. Nos. 16 and 19, which although identical in cultural characters with "paratyphoid" bacilli agglutinated rather feebly with our sera as compared with standard strains of B. suipestifer and B. paratyphosus (B).

It may be added that none of our sera agglutinated B. typhosus, B. enteritidis Gaertner, or B. paratyphosus (B) in higher dilutions than 1 in 100.

(3) Absorption tests.

The absorption method was introduced by Castellani (1902) and was at first used mainly for the diagnosis of mixed infections. An obvious extension of the principle underlying the absorption method is that, if all the agglutinins formed in response to vaccination with a given organism are removed from the serum not only by it but also by some heterologous organism, the two organisms must be identical.

The method, if employed for a number of strains, is very laborious and in the case of the "paratyphoid" group of bacilli it can be used in a much simpler form. It has been shown that the members of this group of bacilli fall into two and only two classes, namely, one corresponding in all respects to $B$. suipestifer (or aertryck) and one corresponding to $B$. paratyphosus (B). It follows, therefore, that a serum which has been absorbed by the heterologous organism, is all that is needed for the identification of an unknown strain belonging to this group. Thus if a paratyphosus (B) serum is absorbed with B. suipestifer until the heterologous agglutinin is removed, it will still agglutinate 
paratyphosus (B) but not B. suipestifer, and by the use of such a serum it is perfectly simple to identify an unknown strain, since an organism which gives the correct cultural reactions and is agglutinated in high dilution by paratyphosus (B) or suipestifer sera, can only be $B$. suipestifer or B. paratyphosus (B), so far as is known. It was found unnecessary to absorb the sera with all the unknown organisms, and we have used almost entirely $B$. paratyphosus (B) sera absorbed with $B$. suipestifer, and B. suipestifer sera absorbed with B. paratyphosus (B). We have however checked our results for some strains by absorbing different sera with unknown strains according to the original method of Castellani.

The method of partial absorption was found to be very satisfactory and the results were concordant; no discrepancy was revealed when the sera were absorbed by unknown strains. It is desirable nevertheless to remove the heterologous agglutinin very completely since different strains vary slightly in the readiness with which they absorb agglutinin from, and are agglutinated by, a given serum. This variation represents nothing more than a certain individuality among members of the same group of bacilli, and is in no way comparable to the distinction between $B$. suipestifer and B. paratyphosus (B). The bacillus "F," recently described by Williams, Rundle and Murray (1910), is an interesting example of such individuality. These authors obtained from cases of summer diarrhoea seven strains, three of which were identical with $B$. suipestifer, whereas four gave anomalous absorption reactions, and were regarded by the writers as being intermediate between $B$. suipestifer and B. paratyphosus (B) and were called bacillus " $F$." Dr. Williams very kindly furnished us with a strain of this organism, and also a serum homologous for it. We found that the bacillus gave the cultural tests characteristic of the "paratyphoid " group. Agglutination and absorption tests gave the following results, the organism being compared with recognised strains of $B$. paratyphosus (B) and $B$. suipestifer :

TABLE V. Agglutination reaction. Macroscopic Method.

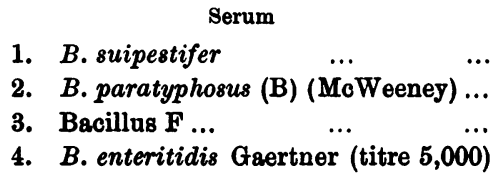

$\begin{array}{ccc}\text { Bacillus F } & \begin{array}{c}\text { Lab. strain } \\ \text { B. suipestifer }\end{array} & \begin{array}{c}\text { Paratyph. (B) } \\ \text { (McWeeney) }\end{array} \\ 10,000 & 10,000 & 5,000 \\ 5,000 & 10,000 & 20,000 \\ 5,000 & 5,000 & 2,000 \\ <100 & <100 & <100\end{array}$


TABLE VI. Absorption tests.

1. Bacillus $F$.

$\begin{array}{ccc}\text { Bacillus F } & \text { B. suipestifer } & \begin{array}{c}\text { Paratyph (B) } \\ \text { (McWeeney) }\end{array} \\ 5,000 & 5,000 & 2,000 \\ <200 & <200 & <200 \\ <200 & <200 & <200 \\ 5,000 & 5,000 & <200\end{array}$

2. B. suipestifer.

Original titre...

Abs. with B. paratyph. (B)

$\begin{array}{rrr}10,000 & 10,000 & 5,000 \\ 10,000 & 10,000 & <200 \\ <50 & <50 & <50\end{array}$

3. B. paratyphosus (B).

$\begin{array}{ccrrr}\text { Original titre... } & \ldots & 5,000 & 10,000 & 20,000 \\ \text { Abs. with B. suipestifer } & \ldots & <400 & <400 & 10,000 \\ \text {, Bacillus F } & \ldots & <400 & <400 & 10,000\end{array}$

It is perfectly clear that Bacillus $F$ is indistinguishable from recognised strains of $B$. suipestifer and that the slight differences noted by Williams, Rundle and Murray disappear when the sera are fairly completely absorbed and the agglutination limits are subsequently determined. These authors ${ }^{1}$ have accepted the results of our observations upon Bacillus $F$ and also our interpretation of the slightly different results which they obtained; and they now regard Bacillus $F$ as identical with $B$. suipestifer and not as a separate strain.

The general results obtained by the absorption method are set forth in Tables VII-X ${ }^{2}$. Table VII shows the results obtained with recognised standard strains of the $B$. suipestifer and B. paratyphosus (B). The strains obtained for investigation have been arranged in three groups, corresponding to their mode of origin, so far as it is known.

Group I (Table VIII) includes all strains obtained from food or from outbreaks of illness, clinically resembling acute food-poisoning. Group II (Table IX) includes all the strains obtained from cases of paratyphoid fever, and from persistent paratyphoid carriers (Danerträger). Group III (Table X) contains strains concerning which information is inadequate or absent.

1 Private communication kindly made by Dr Williams.

3 Absorption tests were also made with the sera $A$ and B; the results have been omitted since they were identical with those obtained with sera $C$ and $D$, which are recorded in Tables VII-X. 
With two exceptions, the strains included in Group I are identical with the standard strains of $B$. suipestifer. Strain No. 16 was obtained from a severe outbreak of food-poisoning caused apparently by infected goose-flesh. It has all the cultural characters of the "paratyphoid" group, but agglutinates very slightly with suipestifer and paratyphosus (B) sera. As far as they go, its agglutination reactions suggest that it is a strain of B. suipestifer, but it agglutinates so feebly that absorption tests were of no help in identifying it. This is the only strain we have found to be culturally identical with $B$. suipestifer, but which was agglutinated only slightly by suipestifer and paratyphosus (B) sera.

Strain No. 18 is extremely interesting. It was obtained from the faeces of patients suffering from acute gastro-enteritis, clinically resembling food-poisoning. Subsequent enquiry showed that the outbreak

\section{TABLE VII. Absorption test.}

Examination of standard strains. -

Strains examined

(a) B. paratyph. (B); Schottmüller

(b)

(c) B.suipestifer; laboratory strain

(d)

(e)

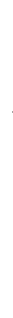

$B$. suipestifer serum. Agglutination titre before and after absorption with $\overbrace{\begin{array}{c}\text { Original } \\ \text { titre }\end{array}}^{\begin{array}{c}\text { Titre after } \\ \text { absorption }\end{array}}$ $5,000<200$ $5,000<100$ 10,000 10,000 10,000
B. paratyphosus (B) serum. Agglutination titre before and after absorption with B. suipestifer

Original
titre $\quad \begin{gathered}\text { Titre after } \\ \text { absorption }\end{gathered}$
$20,000 \quad 10,000$ $20,000 \quad 10,000$ $5,000 \quad 10,000<200$ $5,000 \quad 5,000<200$ $5,000 \quad 10,000<400$

\section{TABLE VIII. Absorption test.}

GrodP I. Examination of strains obtained from food or from cases of acute gastro-enteritis.

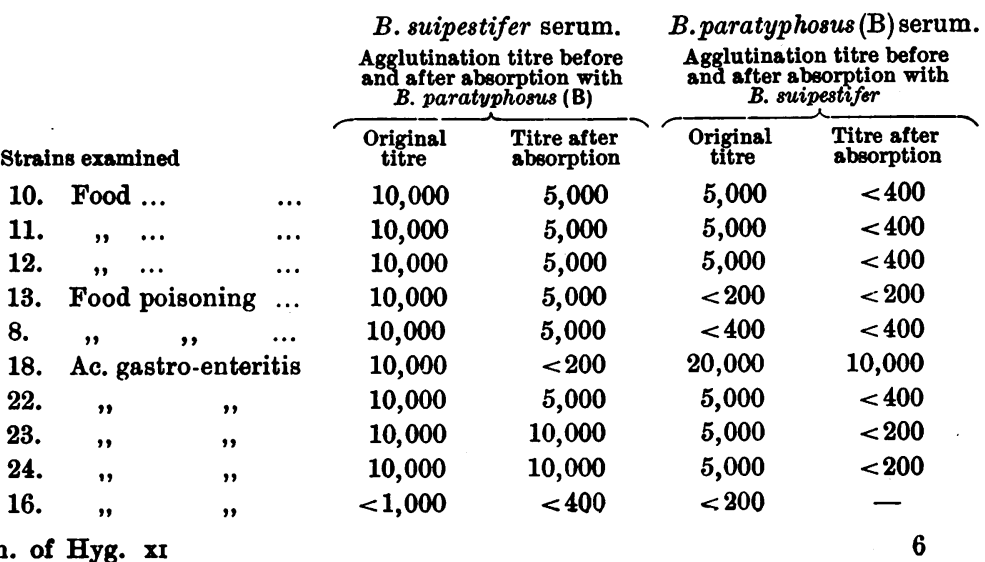

(3) No. $12 .$, , ...

(4) No. 13. Food poisoning ...

(5) No. $8 . \quad, \quad, \quad$,

(6) No. 18. Ac. gastro-enteritis

(7) No. 22.

(8) No. 23.

(9) No. 24.

(10) No. 16. , ,

Journ. of Hyg. xI

B. suipestifer serum. Agglutination titre before
and after absorption with and a paratyphosus (B)
B. titre absorption

\footnotetext{
Journ. of Hyg. xI
} 


\section{TABLE IX. Absorption test.}

GROUP II. Strains from cases of paratyphoid fever or persistent " paratyphoid" carriers.

\section{Strains examined}

(1) No. 1. Paratyphoid fever...

(2) No. 2. ,, carrier

(3) No. 3 .

(4) No. 4.

(5) No. 5.

(6) No. 14.

(7) No. 15.

(8) No. 17.

(9) No. 20.

.

B. paratyphosus (B) serum. Agglutination limits before and after absorption with

Agglutination limits th and after abormits before B. paratyphosus (B)

$\begin{array}{rcccc}\begin{array}{c}\text { Original } \\ \text { titre }\end{array} & \begin{array}{c}\text { Titre after } \\ \text { absorption }\end{array} & \begin{array}{c}\text { Original } \\ \text { titre }\end{array} & \begin{array}{c}\text { Titre after } \\ \text { absorption }\end{array} \\ 5,000 & <200 & 20,000 & 10,000 \\ 10,000 & 100 & 20,000 & 10,000 \\ 5,000 & <400 & 20,000 & 10,000 \\ 5,000 & <400 & 20,000 & 10,000 \\ 5,000 & <200 & 20,000 & 10,000 \\ 5,000 & <400 & 20,000 & 10,000 \\ 5,000 & <400 & 20,000 & 10,000 \\ 5,000 & <400 & 10,000 & 10,000 \\ <400 & - & <200 & -\end{array}$

TABLE X. Absorption test.

Group III. Strains whose origin and pathogenic relationship are unknown or doubtful.

\begin{tabular}{|c|c|c|c|c|c|c|c|c|}
\hline & & & & & \multicolumn{2}{|c|}{$\begin{array}{l}\text { B. suipestifer serum. } \\
\text { Agglutination limits before } \\
\text { and after absorption with } \\
\text { B. paratyphosus (B) }\end{array}$} & \multicolumn{2}{|c|}{$\begin{array}{l}\text { B.paratyphosus (B) serum. } \\
\text { Agglutinstion titre before } \\
\text { and after absorption with } \\
\text { B. suipestifer }\end{array}$} \\
\hline \multicolumn{5}{|c|}{ Strains examined } & $\underset{\text { titre }}{\text { Original }}$ & $\begin{array}{l}\text { Titre after } \\
\text { absorption }\end{array}$ & $\begin{array}{c}\text { Original } \\
\text { titre }\end{array}$ & $\begin{array}{l}\text { Titre after } \\
\text { absorption }\end{array}$ \\
\hline (1) & No. 6. & Healthy & $\operatorname{man}$ & $\ldots$ & 5,000 & $<400$ & 20,000 & 10,000 \\
\hline (2) & No. 7. & ", & $"$ & $\cdots$ & 5,000 & $<200$ & 20,000 & 10,000 \\
\hline (3) & No. 19. & , & ., & $\ldots$ & 10,000 & $<100$ & 5,000 & $<200$ \\
\hline (4) & No. 9. & "Sick" & $\operatorname{man}$ & $\ldots$ & 10,000 & 10,000 & 5,000 & $<200$ \\
\hline (5) & No. 21. & Water & $\cdots$ & $\cdots$ & 2,000 & $<200$ & 20,000 & 10,000 \\
\hline
\end{tabular}

had not been caused by diseased food, but was possibly brought about by a human paratyphoid carrier, and that it is not a genuine example of food-poisoning.

All the strains included in Group II are identical with B. paratyphosus (B), except No. 20, which was not agglutinated by suipestifer, paratyphosus (B) (or Gaertner) sera, although its cultural characters were identical with those of $B$. paratyphosus (B).

No definite history of the strains included in Group III could be obtained. Three were from healthy men, but it was not known whether they were true paratyphoid carriers, or whether they had recently suffered from paratyphoid fever or food-poisoning. One was from a "sick" man, but the nature and causation of the illness could not be ascertained by us. Strain No. 21 was isolated from a well water which 
was otherwise bacteriologically satisfactory; no further information could be obtained with regard to it, except that attacks of jaundice had occurred among those who drank the water.

It thus appears that with two exceptions (Nos. 16 and 19) all the strains which we examined could be identified without difficulty by the absorption method as either B. suipestifer or B. paratyphosus (B). Every strain which was agglutinated by suipestifer and paratyphoid sera gave perfectly sharp and definite results when tested by the absorption method. The strains, which were obtained from undoubted cases of paratyphoid fever or persistent carriers, were all identical with standard strains of B. paratyphosus (B), while the organisms obtained from food or from outbreaks of illness definitely attributable to infection by food were identical with $B$. suipestifer.

\section{Discussion of results.}

There seems to be no doubt that those strains of bacilli which, by virtue of their cultural characters and agglutination reactions, belong to the paratyphoid group, can be further separated into two classes by means of the absorption method ${ }^{1}$. We regard the distinction which is revealed by this method as a real one, and we consider that, although they are closely related, $B$. suipestifer (with which $B$. aertryck is identical) and $B$. paratyphosus (B) are different organisms.

It has now been shown that $B$. paratyphosus (B) causes not only paratyphoid fever, but also sudden acute illness (Bainbridge and Dudfield, 1911); and the distinction formerly drawn on clinical grounds between infection by $B$. suipestifer and by $B$. paratyphosus (B) can no longer be maintained. Nevertheless, the distinction between these two organisms is of importance from an epidemiological point of view, since they appear to have a different distribution in nature.

Although we have not examined a very large number of strains, all the strains of $B$. paratyphosus (B) in our series were derived from man. We are disposed to regard the human alimentary canal (including the bile passages) as the normal habitat of $B$. paratyphosus (B) while admitting that paratyphoid "carriers" may cause infection not only directly but also indirectly by contaminating otherwise sound food,

1 Dr H. R. Dean has examined a number of the strains of our series by the complement deviation method; his results confirm our observations and show that strains of $B$. suipestifer and $B$. paratyphosus (B) can be differentiated from one another. (Private communication.) 
just as is the case with typhoid carriers. Under these circumstances it is to be expected that the bacilli may occasionally be found in food, polluted by a carrier, although we have not met with such an instance.

Lentz (1905) appears to have been the first to recognise the existence of persistent paratyphoid carriers; in 1905, he recorded five cases, one of whom had possibly given rise to a small epidemic of paratyphoid fever. During the investigation of a typhoid epidemic, Wernicke (1907) found a paratyphoid carrier, who was employed in a milk shop; and the evidence suggested that a number of cases of paratyphoid fever were caused by this carrier.

More recently, Prigge (1909) bas described several persistent carriers, whose serum agglutinated paratyphoid bacilli, and who had either suffered from paratyphoid fever, or had been in contact with cases of paratyphoid fever. Strains Ncs. 2, 3, 4, and 5, of our series were obtained from these cases. The frequency in carriers of disease of the bilepassages is also of interest. Hamilton (1910) examined twenty-four cases of chronic cholecystitis and found five carriers, and Gaethgens (1907) met with two carriers, who were suffering from chronic cholelithiasis; almost all these carriers were women. No paratyphoid carrier has yet been recorded in this country although the outbreak of illness, from which strain No. 18 was obtained, was thought, mainly on epidemiological grounds, to be caused by a carrier ${ }^{1}$.

The part played by carriers in the causation of paratyphoid fever has still to be worked out, but it seems possible that careful search for carriers among those in actual contact with cases of paratyphoid fever may furnish a clue to the epidemiology of that disease.

In contrast to $B$. paratyphosus (B), it appears from our observations that the usual habitats of $B$. suipestifer are first the alimentary canal of the pig and perhaps other domestic animals, and, secondly, meat derived from such animals. No unimpeachable evidence has been brought forward as to the prevalence in this country of $B$. suipestifer in food or in the lower animals. The observations of Morgan² (1905), who obtained this organism by injecting into guinea-pigs mixed cultures from the faeces of pigs, are open to criticism, since Petrie and O'Brien (1910) have shown that it may often be obtained from healthy guinea-

1 A recent epidemic of gastro-enteritis at Wrexham is attributed to infection by a paratyphoid carrier. (See p. 89 this Journal. ED.)

2 Dr Morgan himself now regards the results of these experiments as inconclusive. (Private communication.) 
pigs; and there is other evidence that it may be obtained from guinea-pigs inoculated with material in which this bacillus was certainly not present.

In Germany, however, both Uhlenbuth (1908) and Seiffert (1909) have obtained $B$. suipestifer from the alimentary canal of the pig in a fair percentage of cases; and the strains Nos. 10,11 and 12 of our series, which were isolated from apparently healthy food by German workers, were identical with standard strains of $B$. suipestifer.

Although the recent observations of Sobernheim (1910) and of Zwick and Weichel (1910) seem to show that bacilli of the "paratyphoid" group are much less often present in food (in some parts of Germany) than was at first supposed, there is no doubt of their occurrence in apparently healthy food. Under these circumstances they must, from time to time, be ingested by man, although their stay in the human alimentary canal is apparently very transitory. Thus Conradi (1909) found that when meat containing these bacilli was eaten by man, they could be obtained from the faeces on the following day, but not subsequently. Prigge (1909) also noticed that individuals who ate such meat, showed no evidence of infection, and that the transitory occurrence of bacilli of the "paratyphoid" group in their alimentary canal did not increase the agglutinating power of their blood for these bacilli. It may be noted that persistent $B$. suipestifer carriers have not been observed in man. If, as our observations lead us to suppose, these writers were dealing with strains of $B$. suipestifer it would appear that the isolation on a single occasion of $B$. suipestifer from the faeces of a healthy man, whose serum does not agglutinate the organism in higher dilutions than that of normal individuals, has no pathological significance.

Nevertheless, outbreaks of acute gastro-enteritis have occurred (Durham, 1898, and De Nobele, 1898) in which the epidemiological evidence pointed to infection by food, in which $B$. suipestifer was isolated both from the food and from the excretions or organs of the patients, and in which the serum of the patients agglutinated this organism in high dilutions. Such evidence that $B$. suipestifer is capable of causing acute infection cannot be disregarded, although the rôle of this organism in swine fever may arouse scepticism as to its capacity to initiate an infection. In swine fever and epizootics among guinea-pigs, it appears to be merely a secondary invader and not primarily a cause of the infection ${ }^{1}$; and it would be a matter of great

1 Uhlenhuth and Hübener (1908); Petrie and O'Brien (1910). 
'interest if $B$. suipestifer should prove to occupy a similar subsidiary position in relation to "food-poisoning" outbreaks in man.

Further investigation is needed in order to account for the occurrence of this organism in man at one time as an apparently harmless saprophyte, at another in association with acute gastro-enteritis.

\section{SUMMARY AND CONCLUSIONS.}

1. The term "paratyphoid group of bacilli" has been confined in the present enquiry to those strains which in their cultural characters and agglutination reactions are indistinguishable from $B$. suipestifer and $B$. paratyphosus (B). B. enteritidis Gaertner and $B$. paratyphosus (A) are excluded.

2. The strains of bacilli belonging to the "paratyphoid" group can be separated into two classes by means of the absorption method, namely one group identical with recognised, standard strains of $B$. suipestifer and one identical with standard strains of $B$. paratyphosus (B); and we regard these two bacilli as separate organisms.

3. In our experience, $B$. suipestifer has been found only in food or in outbreaks of acute illness attributable to food-poisoning, whereas $B$. paratyphosus (B) has been found in cases of paratyphoid fever or in persistent paratyphoid "carriers."

4. We are disposed to put forward the suggestion indicated by these observations, that these two organisms have a different distribution in nature, the normal habitat of $B$. suipestifer being the alimentary canal of the pig (and other animals) and of food derived from such animals, whereas the normal habitat of $B$. paratyphosus (B) is the human alimentary tract (including the gall-bladder).

5. The examination of cultures from the faeces and urine of 300 typhoid convalescents was completely negative, neither $B$. suipestifer nor $B$. paratyphosus (B) being obtained. These observations confirm those of other writers, and, apart from carrier cases, the occurrence of $B$. paratyphosus (B) in healthy human beings appears to be unknown in this country.

Our thanks are due to Drs Fisher, Trautmann, Uhlenhuth, Williams, Rommeler, Prigge, Schern, Friedrichs, Savage and Fowler, who have very kindly supplied us with strains of bacilli for investigation. 


\section{REFERENCES.}

Bainbridge, F. A. (1909). On the paratyphoid and food poisoning bacilli, and on the nature and efficiency of certain rat viruses. Journ. of Path. and Bact. Vol. XIII. p. 443.

(1910). An outbreak of gastro-enteritis due to B. paratyphosus (B). Brit. Med. Journ. Vol. II. p. 1515 .

Bainbridge and DUdField (1911). An outbreak of gastro-enteritis due to B. paratyphosus (B). Journ. of Hygiene, Vol. xI. p. 24.

Bock (1906). Arb. a. d. Kaiserlich. Gesundheitsamte, Berlin, Vol. xxIv. p. 227.

Вочсотт, A. E. (1906). Observations on the bacteriology of paratyphoid fever, and on the reactions of typhoid and paratyphoid sera. Journ. of Hygiene, Vol. vi. p. 33.

Castellani, A. (1902). Die Agglutination bei gemischter Infection und die Diagnose der letzteren. Zeitschr. f. Hygiene, Leipzig, Vol. xL. p. 1.

Conradi (1904). Über Mischinfection durch Typhus- und Paratyphusbazillen. Deutsche med. Wochenschr. p. 1165.

(1909). Klin. Jahrbuch. Vol. xxI. p. 421.

De Nobele (1898). Kolle u. Wassermann's Handb. Vol. II. p. 655. (v. Ermengen.)

Durham (1898). An address on the present knowledge of outbreaks due to meat poisoning. Brit. Med. Journ. Vol. II. p. 1797.

Feyfer and Kayser (1902). Eine Endemie von Paratyphus. München. med. Wochenschr. p. 1692.

Fischer (1902). Zur Aetiologie der sogenannten Fleischvergiftungen. Zeitschr. f. Hyg. Vol. xxxIx. p. 447.

- (1903). Zur Epidemiologie des Paratyphus. Koch's Festschrift, p. 271.

Gamthans, W. (1907). Über die Bedeutung des Vorkommens der Paratyphusbazillen (Typhus B.). Arb. a. d. Kaiserlich. Gesundheitsamte, Vol. xxv. p. 203.

Hamilton (1910). The value of Opsonin determinations in the discovery of typhoid carriers. Journ. of Infect. Diseases, Vol. vir. p. 393.

Hübener (1908). Über das Vorkommen von Bakterien der Paratyphus-B.gruppe in der Aussenwelt. Deutsche med. Wochenschr. p. 1044.

Kotscher (1906). Kolle und Wassermann's Handbuch der Pathogenen Mikroorganismen. Supplement, Bd. I. S. 655.

Kutscher and Meinicke (1906). Vergleichende Untersuchungen über ParatyphusEnteritis und Mäusetyphusbakterien und ihre immunisatorischen Beziehungen. Zeitschr. f. Hyg. Vol. LII. p. 301.

Jenntz (1905). Über chronische Typhusbazillenträger. Klin. Jahrb. Vol. xIv. p. 475.

Morgan, H. de R. (1905). Some observations upon the micro-organisms of meat and their allies. Brit. Med. Journ. Vol. I. p. 1257.

(1906). Upon the bacteriology of the summer diarrhoea of infants. Brit. Med. Journ. Vol. I. p. 908.

(1907). Upon the bacteriology of the summer diarrhoea of infants. Brit. Med. Journ. Vol. II. p. 16. 
Morgan and Ledingham (1909). Upon the bacteriology of summer diarrhoea of infants. Proc. Roy. Soc. of Med. (Epid. Section), Vol. vir.

O'Brien, R. A. (1910). Guinea-pigs as chronic carriers of an organism belonging to the food poisoning group. Journ. of Hygiene, Vol. x. p. 231.

ORR (1908). Report to Yorkshire Local Authorities Committee.

Petrie and O'Brien (1910). A guinea-pig epizootic associated with an organism of the food poisoning group, but probably caused by a filter passer. Journ. of Hygiene, Vol. x. p. 287.

PrigGe and SACHS-MüKE (1909). Paratyphusbazillenåusscheidung bei Kranken und Gesunden. Klin. Jahrb. Vol. xxIr. p. 237.

Rommeler (1909). Über die Befunde von Paratyphusbazillen in Fleischwaren. Centralbl.f. Bakt. Orig. Vol. L. p. 501.

SAvage (1908-1909). Report upon the presence of paratyphoid bacilli in man. Local Govt. Board Reports, Appendix, B. No. 4, p. 316.

SchotTMÜLler (1900). Über eine das Bild des Typhus bietende Erkrankung hervorgerufen durch typhusähnliche Bazillen. Deutsche med. Wochenschr. p. 511.

- (1901). Weitere Mitteilungen uiber mehrere das Bild des Typhus bietende Kranksheitsfälle hervorgerufen durch typhusähnliche Bazillen (Paratyphus). Zeitschr. f. Hyg. Vol. xxxvi. p. 368.

SeIFrert (1909). Studien zur Salmonella Gruppe. Paratyphus-B.gruppe Zeitschr. f. Hyg. Vol. LxiII. p. 273.

Sobernheim (1910). Über Fleischvergiftung. Centralbl.f. Bakt. Vol. xuvir. Ref. Beit. zu Abteil. p. 170.

Sobernheim and Seltamann (1910). Weitere Untersuchungen der Enteritisbakterien. Zeitschr. f. Immunitäts-Forschung. Vol. vi. p. 401.

UhLENhuth and HüBener (1908). Untersuchung über das Wesen und die Bekämpfung der Schweinepest. Arb. a. d. Kaiserlich. Gesindheitsamte, Vol. xxvII. p. 425.

Wernicke (1907). Die Typhusepidemie in der Stadt Posen im Jahre 1905. Klin. Jahrb. Vol. xviI. p. 163.

Williams, Murray and Rundle (1910). Further researches into the bacteriology of epidemic summer diarrhoea. Lancet, Vol. II. p. 730.

Zwick and Weichel (1910). Zur Frage des Vorkommens der sogenannten Fleischvergiftungserreger in Pökelfleischwaren. Arb. a. d. Kaiserlich. Gesundheitsamte, Vol. xxxIII. p. 250. 